\title{
Quality improvement for self-confidence, critical-thinking, and psychomotor skills in basic life support of nursing health professionals through case-scenario simulation training
}

\author{
Sarah J. Lee*1,2, Wendy Johnson ${ }^{1,3}$, Teneka Liddell ${ }^{1}$ \\ ${ }^{1}$ Dept of Education, John D. Dingell VA Medical Center, Detroit, MI, USA \\ ${ }^{2}$ Division of Pulmonary and Critical Care Medicine, Wayne State University School of Medicine, Detroit MI, USA \\ ${ }^{3}$ Nursing Section, John D. Dingell VA Medical Center, Detroit, MI, USA
}

Received: February 11, 2021

DOI: $10.5430 /$ jnep.v11n8p23
Accepted: March 21, 2021

Online Published: April 11, 2021

URL: https://doi.org/10.5430/jnep.v11n8p23

\begin{abstract}
Background: Recognition and timely management of medical emergencies in non-critical care units are essential in initiating and delivering high quality care. Simulation training is a constructive tool that can be utilized to refresh and maintain knowledge and skills for staff that may not encounter medical emergencies frequently. This study examined staff that work at the John D. Dingell VA Medical Center Community Living Center (CLC), a subacute and inpatient rehabilitation unit, on their critical thinking skills, knowledge, role responsibilities and confidence levels prior to and after implementation of a mixed intervention of a one-hour webinar didactic and one-hour case-based simulation with debriefing. The purpose of the study was to improve non-critical care staff critical thinking, knowledge and confidence when working with a deteriorating patient.

Methods: A pretest-posttest study design was used to conduct the study. Pre and post surveys were given to 42 health professionals which included registered nurses (RN), licensed practical nurses (LPN) and nursing aides after participating in a case scenario using a high-fidelity mannequin to simulate a medical emergency. Analyses were performed using the two-tailed $t$-test with $p$-value significance of less than .05 using Excel and JMP by SAS.

Results: Among the 42 participants, there was a significant improvement in confidence for recognizing signs of patient deterioration for timely activation of code team $(p<.001)$. Critical thinking skills and knowledge on appropriate activation of the type of response team based on patients' speed of deterioration also improved after the intervention $(p<.001)$. Overall, the staff felt more comfortable, confident and knowledgeable concerning their roles and local policy of emergent situations.

Conclusions: A team-based case scenario simulation course may improve non-critical care nursing staff confidence, knowledge and critical thinking as it pertains to activation of code teams and willingness to actively participate in medical emergencies.
\end{abstract}

Key Words: Quality improvement, Self-confidence, Critical-thinking, Psychomotor skills, Case-scenario simulation training

\section{INTRODUCTION}

Timely recognition and management of deteriorating hospitalized patients is essential for favorable patient outcomes, especially pertinent for those who require resuscitation. ${ }^{[1-3]}$ Bedside nursing staff continuously assess patients thereby are positioned to be the first to detect clinical worsening, USA.

Published by Sciedu Press 
activate the code response team, and initiate resuscitation. Non-critical care ward nurses, however, may hesitate in activating a code response team or medical emergency team due to a number of factors including failure to recognize early signs of patient deterioration, fear of bypassing physician hierarchies, and confusion or fear of calling the wrong code team. ${ }^{[4,5]}$ In many tertiary hospitals, different code response teams are designated for specific medical emergencies. ${ }^{[4]}$ For example, a Code Blue Team would include among other members, an anesthesiologist and a pharmacist, while a Rapid Response Team or Stroke Team would not. In some hospitals, code team members observed delays in initiating chest compressions, problems with correct placement of the automated external defibrillator (AED) pads, and trouble locating resuscitation supplies. ${ }^{[6,7]}$ Delays for resuscitation are exacerbated if non-critical care ward nurses are unsure of their role in medical emergencies and rely on the arrival of the code team for instructions on initiating the Basic Life Support (BLS) or Advanced Cardiovascular Life Support (ACLS) protocols. ${ }^{[4]}$ Increased self-confidence, recently completed cardiopulmonary resuscitation (CPR) retraining, and experience with CPR improves the quality and timing of BLS by hospital nurses. ${ }^{[8,9]}$ Since many nurses in the workforce may not encounter medical emergencies frequently, simulation training may be a valuable tool to refresh and maintain their knowledge and skill so that they can deliver high quality care when the need arises. ${ }^{[10,11]}$

Within the John D Dingell VA Medical Center in Detroit Michigan, a unit called the Community Living Center (CLC) exists, which is an equivalent level-of-care for acute and sub-acute inpatient rehabilitation or skilled nursing facilities. Even though all the nursing staff are required to maintain their BLS certification via the American Heart Association's requirement at minimum every two years, they expressed feeling underprepared and unconfident in the face of a real situation possibly due to the infrequent exposure to medical emergencies. We hypothesized that staff confidence, critical thinking, and knowledge gaps would improve with handson practice in a simulated case scenario while familiarizing themselves with the facility's resuscitation equipment and code cart.

\section{Literature review}

Experiential learning with a simulator has shown to improve knowledge retention, satisfaction, and confidence among learners, even among experienced nursing staff. ${ }^{[10-12]}$ Anxiety is common and universal among nurses of all levels and duration of experience, from new graduates to highly-skilled proficient nurses, which subsequently can lead to delays in cardiopulmonary resuscitation, manifesting as struggles with the resuscitation equipment, performing CPR or ventilation with bag-valve-mask, or team communication. ${ }^{[10,11,13]}$ Simulation training can improve staff response times in recognizing and acting in clinical emergencies, specifically life-saving actions such as chest compressions, AED use, and epinephrine administration. ${ }^{[14,15]}$ Simulation's other advantage is creating an open educational environment that frees learners to make mistakes without risk to patient safety, which further reinforces memory and retention. ${ }^{[16,17]}$ Finally, skill and knowledge decay is known to occur over time after training, so team-based simulation using high-fidelity mannequins is endorsed by the American Heart Association (AHA) to enhance retention of the resuscitation training. ${ }^{[18]}$

Communication, specifically "Activation of the emergency response system", is a recognized important aspect of resuscitation and emergency care of a deteriorating patient in a facility, such that it is a component of the AHA's inpatient "Chain of Survival" algorithm. ${ }^{[19]}$ For interprofessional communication, both the Joint Commission and Institute of Health endorsed standardizing the approach to handoff communication. ${ }^{[20]}$ One study on interprofessional verbal communication found that nursing students were in favor of using the tool Situation, Background, Assessment, Recommendation (SBAR) to relay clinical information to a physician because of the concise, clear structure and helped to diminish anxiety or uncertainty students felt in speaking with a physician. ${ }^{[21]}$ Another study found nursing learners' exposure to SBAR during a high-fidelity simulation experience improved their communication skills and competence in patient care and safety according to the Quality and Safety Education for Nurses (QSEN)-based rubric assessment. ${ }^{[22,23]}$

\section{METHOD}

\subsection{Study design}

This is a pretest-posttest study design entailing surveys of nursing health professionals such as licensed practical nurses (LPN), registered nurses ( $\mathrm{RN})$, and nursing aides, in response to a mixed intervention of a one-hour webinar didactic and one-hour case-based simulation with a debriefing session. Through simulation using a high-fidelity mannequin, the purpose of this initiative was to improve the CLC unit staffs' critical thinking and confidence to manage a clinically deteriorating patient prior to a code response team arrival, with the hope that reinforcing timely appropriate decisions and actions will improve patient outcomes. Our aim was for staff to gain critical thinking of their role and responsibilities for the following: activating the appropriate type of code response team, using the Code Cart contents appropriately including the AED and bag-valve mask, communicating with each other and the Code Team leader during a medical emergency, 
and improving their confidence in initiating BLS resuscitation independent of the Code Team.

The training team consisted of the following: a nurse educator who was a certified BLS and ACLS instructor and $\mathrm{PhD}$ candidate in nursing education, a critical care medicine physician who was the medical director of the simulation center and experienced in simulation methodology, and the CLC unit assistant clinical nurse manager (A-CNM) who was a teaching faculty at a local nursing school. The CLC A-CNM collected staff observations and feedback on knowledge gaps, which formed the basis of the course content. This training team developed the materials for this course, which consisted of an electronic didactic webinar, a realistic case scenario with targeted learning objectives, and pre- and posttests measuring confidence and medical knowledge. The materials were modeled after previously validated tools, but questions were added specific to our facility's needs, such as discerning the types of code teams. ${ }^{[24,25]}$

The CLC nursing leadership approved and scheduled dedicated education time for all nursing staff to attend the training course. They were all assigned to review the electronic didactic presentation and complete the pre-test prior to their assigned session. During a three-day period, the staff were divided into groups of five or six learners, an ideal group size for effective simulation learning. ${ }^{[26]}$ Each group was assigned a one-hour time slot to participate in a team-based case scenario using a high-fidelity mannequin and staggered in a manner that did not compromise patient care. Each of the sessions consisted of a ten-minute pre-briefing to orient learners to the simulation environment and state the "simulation contract", which is the necessity for learners to suspend disbelief and act as one would in a real patient situation. During pre-briefing, it was made clear to learners that these sessions were used for educational purposes only and not to be used for disciplinary action or for employees' performance record. The pre- and post-test were anonymous so that no identifying information of the learners were recorded or tracked to further assure staff of a safe learning environment and to encourage full participation. Sessions were video-recorded for immediate viewing by the learners during debriefing to aid in self-reflection then deleted. Participation was voluntary and learners were offered an option to opt out at any time if they felt uncomfortable during the training. The team-based simulation case scenario then ran for a maximum of $15 \mathrm{~min}$ utes. This was immediately followed by a debriefing session led by all three of the training team members. The 20 to 30 minute debriefing allowed time for self-reflection on learners' performance, demonstrate correct use of the equipment and code cart contents, review the BLS algorithm, review the expectations of the CLC staffs' role prior and during a code, reinforce facility's protocols for code team activation, discuss best practices for team communication, and address all questions the learners had on clinical management.

\subsection{Equipment/Environment}

Simulation sessions were held in the Detroit VA simulation procedural room, which was set up to emulate an in situ inpatient room with the Laerdal SimMan 3GTM mannequin lying on a patient bed with a pillow, sheets, and a blanket. The high-fidelity mannequin can exhibit breath and heart sounds, palpable pulses, and some limited speech. The mannequin records quality of cardiopulmonary resuscitation efforts including compression depth and rate, hands-off time, and adequate ventilation. Continuous vital signs were displayed in real-time on a bedside monitor, which included heart rate and rhythm strip, blood pressure, temperature, respiratory rate, and oxygen saturation with pulse oximetry. Next to the mannequin, a simulation Code Cart was placed, which was set-up in similar appearance and content as an actual facility cart with the following: a Zoll $®$ AED/Cardiac Defibrillator with attached training AED pads, nasal cannula, non-rebreather mask, oxygen flow meter, Bag-Valve-Mask, compression backboard, oxygen tank, demo saline bags and tubing, and a clipboard with the facility's Code Blue Run Sheet and the AHA's BLS algorithm cue card. The room also had wall-regulated oxygen, a clock with a minute hand, blood pressure cuff, stethoscope, hand gel, exam gloves, and an intravenous (IV) pole.

\subsection{Personnel}

During the case scenario of a deteriorating patient, the nurse educator's role was an actor simulating a newly graduated nurse who was requesting help from her fellow unit staff, the learners. In the role of the bedside nurse, the nurse educator relayed information to the learners depending on their questions to move the scenario forward i.e. the patient's basic clinical history including past medical history, medications, code status, and reason for admission. The CLC assistant manager silently observed the sessions and tracked the groups' progress using a checklist developed for this training. Immediately after the scenario ended, this checklist guided the debriefing to discuss learning objectives and goal competencies per BLS guidelines and best practices on team communication. The physician educator operated the mannequin by changing vital signs according to the actions and decisions by the learners. The scenario started with learners entering the room and ended with a verbal handoff by one of the learners upon arrival of a physician Code Team leader, who is the physician educator acting as another actor in this role. 


\subsection{Debriefing}

Immediately following each simulation session, faculty asked open-ended questions to stimulate discussion on team's performance and communication. If learners were silent and reluctant to give input, learners would view their performance on the recorded video then were prompted with open-ended questions based on their observations. Ideally, debriefing is where consolidative learning takes place through self-reflection and discussion. ${ }^{[27]}$ Simulation debriefing also reduces anxiety for real-life situations through building self-confidence and developing competency among participants. ${ }^{[12]}$ Open-ended questions can focus on either individual performance or team performance such as the following:

"How did you feel during the scenario?"

"What are things you did well as a team?"

"What are things you wish you did differently/better as a team?"

"What do you think you will you do differently next time?" "What are aspects of the scenario that you feel uncomfortable? Such as activating the Rapid Response Team or Code Blue Team? Using equipment on the Crash Cart? Giving handoff to the Code Team when they arrive? Communicating to each other during a medical emergency?"

During debriefing, if the learners expressed concerns of unfamiliarity with equipment or the BLS algorithm, we paused the discussion, reviewed the Code Cart equipment items systematically, demonstrated the proper use on the mannequin, and invited the learners to practice on the mannequin. We also reviewed the medical knowledge questions from the pretest questionnaire with the group. Trainers can facilitate discussion either by pointing out the favorable actions or areas for improvement after viewing the video or by going through the checklist, but often times the learners themselves brought up these issues without prompting. The checklist was helpful to ensure that we covered educational objectives thoroughly and uniformly session to session. We also used the mannequin's function of evaluating CPR and ventilation quality to give direct feedback. Finally, it was important to engage all learners by allowing time for each learner to comment in the discussion. Therefore, we found a small group of 4 to 6 people ideal, which was enough people to run a Code Blue scenario with each person in different roles but not too many to avoid learners being left out of participating in the scenario and discussion.

\subsection{Assessment}

A pre-test and a post-test on knowledge and confidence included differentiating the code response activation systems and elements of BLS. The questions were developed for this course and internally validated with a small pilot group. Confidence questions were on a 6-point Likert scale then aggregated into confident or not confident groups. All tests were anonymous and lacked identification. Descriptive analysis of the pre and posttest was presented by frequencies and percentages $(n, \%)$. The statistical difference between pre and posttest aggregated results was compared using twotailed $t$-test with a $p$-value significance of less than .05. An IRB waiver for consent and authorization was granted by the Wayne State University and Detroit VA IRB boards.

\section{RESUltS}

The course was attended by 42 voluntary learners which represents more than $90 \%$ of the total unit's staff, comprised of RNs, LPNs, and nursing aides who worked in the facility's CLC rehabilitation unit. Comparing pre to post-simulation questionnaires, there were significant improvements in medical knowledge on key BLS criteria including accurately recalling the timing of one cycle of $\mathrm{CPR}$ (pre $=5 \%$ vs. post $=100 \% ; p<.001)$ and timing of effective Bag-Valve-Mask (pre $=0 \%$ vs. post $=76 \% ; p<.001)$.

There was significant improvement in confidence for recognizing signs of patient deterioration for timely Code Team activation (pre $=31 \%$ vs. post $=90 \% ; p<.001$ ) and confidence in knowing the difference in criteria for activating a Rapid Response and Code Blue (pre $=38 \%$ vs. post $=$ $100 \% ; p<.001)$. The learners also improved their knowledge and critical thinking on differentiating the type of code team activation, the Rapid Response Team vs. the Code Blue Team, based on the clinical scenario and speed of patient deterioration $($ pre $=57 \%$ vs. post $=93 \% ; p<.001)$.

For the post-test after attending the one-hour simulation and debriefing session, almost all learners felt more confident in knowing their role in medical emergencies in both a Rapid Response activation (pre $=21 \%$ vs. post $=100 \% ; p<.001$ ) and a Code Blue activation (pre $=17 \%$ vs. post $=98 \% ; p<$ $.001)$. The group's confidence in performing CPR grew from $35 \%$ confident to $100 \%$ (pre $=15$, post $=42 ; p<.001$ ). There was significant improvement in staffs' confidence in utilizing the equipment in the Code Cart (pre $=24 \%$ vs. post $=83 \%$; $p<.001)$. Although there was improvement, only $60 \%$ of learners post-simulation felt confident in communicating to a physician or Code Team Leader during a medical emergency (pre $=13$, post $=26 ; p=.004)$.

\section{Discussion}

The goal of this pilot study was to evaluate if this case-based simulation course increased the self-confidence, knowledge, skills, and critical thinking in non-critical care ward nursing staff, which could eventually lead to higher quality basic life 
support (BLS) prior to the code team's arrival thereby improving the chain of survival for patients. ${ }^{[2,8]}$ It is known that hospital staff who are inexperienced in emergency situations may have anxiety and reluctance to initiate resuscitation for fear they may perform a wrong action, cause undue harm or trauma to the patient, or are unsure of their roles and responsibilities in relation to a medical emergency code response team. ${ }^{[4,5,9]}$ With immediate and effective CPR as the key component of BLS for favorable patient outcomes, ${ }^{[2,3,28]}$ this course achieved the goals of improving staff confidence for performing CPR from $35 \%$ pre-course to $100 \%$ post-course and improving medical knowledge on how to perform CPR correctly from $5 \%$ to $100 \%$. The low baseline of CPR confidence and knowledge were consistent with prior studies that showed skills and confidence degrade over time after receiving training - more so for personnel working outside of critical care areas due to the lack of exposure to real-world experience and infrequent intermittent training. ${ }^{[7,29-33]}$ One study of 30 licensed nurses, despite a mean clinical experience of 6 years with most holding BLS certification (87\%), found the group of nurses had low baseline scores for CPR. After simulation training, they demonstrated improvement unrelated to their age, experience, unit where they worked, gender, or position. ${ }^{[29]}$ Other studies have found skill decay after 3 to 7 months from training compared to less frequent training intervals. ${ }^{[34,35]}$ In contrast, some studies found that improving self-confidence does not directly correlate with improving competence, partly because novice learners may over-estimate their abilities. ${ }^{[7,24,32,36]}$ Through this course, however, both confidence and knowledge improved, possibly through the feedback based on direct observation of the learners with the simulation and learners' self-reflection during the debriefing. For CPR skills, the training team objectively reinforced positive actions or corrected actions that needed improvement through the high-fidelity mannequin's sensor for chest wall recoil and computerized debriefing summary for speed and depth of compressions. On reviewing the BLS algorithm to aid in quicker recall in an emergency, debriefing included detailed discussion and demonstration of the location of the equipment on the code cart and use of the equipment, such as the correct sequence of steps and handling of the AED, backboard, and bag-valve-mask with oxygen on the mannequin. Using a debriefing tool such as a checklist of learning objectives helped the training team ensure that each session with different groups of learners covered standardized learning objectives despite a learnercentric discussion with open-ended questions. For the airway management portion of BLS, our study's learners demonstrated improved knowledge on how to conduct effective bag-valve-mask from 0 to $100 \%$ of learners but confidence did not rise accordingly from $0 \%$ to $76 \%$ of the learners. This high-fidelity mannequin has a function that measured and reported the percentage of ineffective breaths delivered to the mannequin. Upon hearing the poor percentages and performance, it is possible some of the learners may have become more discouraged in their skills rather than gained confidence despite gaining the theoretical knowledge. For future sessions, individuals who need or want more handson practice for bag-valve-mask use will need to be more effectively identified or allowed more time for everyone to practice on the mannequin with directed feedback. ${ }^{[26]}$

Using a case scenario with simulation helped learners apply knowledge and skills in context and learn a systematic approach, so reasoning and logic are engaged rather than trying to recall rote memorization. One study found learners improved and retained CPR skills using a problem based learning (PBL) style while using a high-fidelity simulation compared to a group that only received a lecture. ${ }^{[37]}$ After six months, the simulation group demonstrated better hands-off time and less pauses in chest compressions to deliver ventilation breaths. ${ }^{[37]}$ For health professionals who rarely encounter medical emergencies, our study showed PBL combined with high-fidelity simulation not only can aid in refreshing BLS skills but also assist learners to acquire positive attitudes, critical thinking and knowledge towards medical emergencies. Our simulation scenario required the learners to prioritize tasks in sequence to the patient's needs and vital signs such that it took the team through early signs of acute respiratory distress but then would later deteriorate to cardiopulmonary arrest. This allowed the learners the chance to activate a Rapid Response Team and a Code Blue Team within the same scenario as the situation worsened. The learners as a team demonstrated their decision-making and skills in trying to stabilize and resuscitate a patient. Most of the learners' self-reflection centered on the appropriateness and timing of the team's decisions and actions. In the pre- and post-tests, learners were given problem-based scenario questions to choose which code team should be activated. The confidence and ability to demonstrate critical thinking for an acutely deteriorating patient were measured through these questions. Confidence in correct action for an acutely deteriorated patient improved from $31 \%$ to $90 \%$, while knowledge on appropriate decision-making improved from $57 \%$ to $93 \%$. Confidence improved to $100 \%$ of learners for both knowing their roles and expectations and on activating a Code Blue appropriately.

Due to the heterogeneity of teaching methods and evaluation, several studies including a systematic review and metaanalysis found inconclusive evidence in undergraduate nursing education that simulation impacts critical thinking. ${ }^{[38]}$ 
However, multiple studies have shown nurses out in the workforce perceive that simulation positively impacts their critical thinking and confidence and improves clinical reasoning skill and related knowledge retention better than didactics alone. ${ }^{[25,39]}$ Prior to attending the simulation, the learners were provided access to the one-hour powerpoint didactic and the pretest at the same time. The information in the didactic did not contain new information to staff but reiterated the basics of the BLS algorithm and facility protocols. Then, the posttest was adminstered immediately after each group attended their assigned one-hour simulation session so that all learners who attended the simulation completed the posttest. Hence, the improvement in post-test scores were attributed to participating in the case-based simulation session and not the didactic. We believe the post-test results show that case-based simulation can be effective for building practical critical thinking skills, such that if learners practice and formulate a systematic approach to one patient scenario, then they can apply this approach to other subsequent clinical situations.

\section{Limitations}

This course was limited in that we were not able to achieve the goal in fully improving confidence in communcating to a physician Code Team Leader. Even though debriefing was facilitated by an interprofessional team of a critical care medicine physician and two nurse educators and included practice of relaying pertinent information via the the SBAR (Situation, Background, Assessment, and Recommendation) handoff, further training on handoff communication beyond this course's format is likely needed.

Another limitation of this study is that we could not directly correlate if the skills and knowledge acquired during simulation training transferred to their real clinical practice or patient outcomes. In our study, our learners improved in both self-confidence and knowledge from pre-test to post-test, thereby meeting the Level 2 criteria on the Kirkpatrick evaluation model, but not a higher level which requires demonstration of changed behavior on real patients or improved patient outcomes. ${ }^{[40]}$ It is unknown if participating in this course positively impacted the timing of BLS resuscitation or the CLC staff decision-making and actions in a real medical emergency, because this is not captured in detail in the electronic medical record documentation and medical emergencies remain infrequent in the CLC unit. Furthermore, our facility at baseline has a much higher survival-to-hospital discharge rate above the national average, so it is difficult to further improve this rate.

A third limitation is that we did not measure hands-on skills for each individual learner pre- and post-test but rather fo- cused on team dynamics and decision-making; however, some feedback on quality of CPR and bag-valve-mask management were given based on the high-fidelity mannequin abilities to record and report hands-off time, effective CPR and effective breath percentages. One study found that in non-critical care areas, despite no difference in the proportion of patients receiving BLS prior to the code team's arrival from before-to-after the staff received the training intervention, the survival-to-hospital discharge rates improved. ${ }^{[41]}$ The authors postulated perhaps the quality of CPR improved with training, which is as important for survival and patient outcomes as the timing of the onset of resuscitation. ${ }^{[41]}$ The exact amount of time delay of resuscitation before it causes irreversible patient harm is unknown and may depend on the underlying cause of the arrest, but the research is clear that earlier access to treatment and initiation of resuscitation, i.e. direct current cardioversion within 4 minutes or less or CPR within 4 to 10 minutes or less of the arrest, improves patient outcomes. ${ }^{[1,2,28,42,43]}$ If resuscitation is started beyond 10 minutes of the onset of the arrest, a metabolic phase entailing a cascade of biochemical pathways are triggered resulting in multi-system organ failure with poor neurologic or functional outcomes or even poor survival. ${ }^{[44]}$ We hope that the confidence gained by the staff would transfer to decreased hesitation and time in activating a Code Team and initating CPR and other necessary BLS resuscitation steps.

A fourth limitation to this study is the small sample size limiting statistical power and generalizability. Demographic and other identifying data were not collected allowing learners to answer more truthfully in their self-reported confidence levels and knowledge without fear of reprisal in job performance evaluations.

Shortly after our course ended, there was a change in the BLS training practice facility-wide. To improve non-critical nursing staffs' knowledge on resuscitation, it is recommended that training ideally should be focused on practical hands-on skills and held in frequent, regular intervals. ${ }^{[9,34]}$ Based on numerous studies, major societies and organizations have recommended health care systems to adopt continuous quality improvement programs to combat skill decay and to assess local needs and resources to benchmark against best practices. ${ }^{[3,34,35,45,46]}$ The US national Veterans Health Administration had adopted the American Heart Association's Resuscitation Quality Improvement (RQI) Program, so that staff can receive more frequent training with direct individual feedback through computer voice-assisted resuscitation mannequins (VAM) ${ }^{[47]}$ Every four months using timed computer simulated case scenarios on a VAM, staff are required to demonstrate their decisions and resuscitation skills by quickly clicking on the computer screen their steps in the 
correct sequence and administer CPR and ventilation breaths to the mannequin, respectively. The computer will speak to the learner to "push harder" or "push faster" or "slow down" during compressions or "slower breath" while giving ventilated breaths via a bag-valve-mask. This is followed by a computer generated debriefing describing which steps needs improved prioritization in decision-making or how to improve a hands-on action. This is an effective training method to refresh resuscitation skills even in the most experienced staff in critical care areas. ${ }^{[4]}$ Our facility has a staged rollout adoption plan, and so far, staff feedback has been favorable. The main drawback in using the VAMs is the system requires initially some trial-and-error for learners to get used to the technology. To overcome this, our facility has a dedicated onsite coordinator and educator readily available to assist staff in troubleshooting. There is still value in intermittent megacode simulation practice with direct in-person debriefing to supplement VAM training, such as through Mock Codes or a course like the one described, in order to address gaps in staff confidence, such as activating the medical emergency response system and to fulfill expectations and responsibilities during a medical emergency. ${ }^{[5,9,31,37,49,50]}$

\section{Conclusion}

A team-based case scenario simulation course may improve non-critical care nursing staff's confidence, knowledge, and critical thinking for activating a code team and willingness to actively participate in medical emergencies. Through a case scenario of a patient who presents in respiratory distress then deteriorates into a cardiopulmonary arrest, staff were able to practice and improve their critical thinking skills to recognize and activate the appropriate medical emergency response system, initiate BLS independent of an inpatient Code Team, and communicate to the Code Team upon their arrival. Posttest results after this 1-hour simulation training showed improved knowledge about the BLS algorithm and the bedside staff's role and expectations in a medical emergency, as well as confidence in differentiating a Rapid Response vs. Code Blue activation, using the Code Cart equipment, and performing resuscitation. For health professionals working in non-critical care areas or have rare exposure to medical emergencies, we recommend more frequent interval training than the 2-year interval BLS certification to maintain knowledge and skills.

\section{Conflicts OF InTEREST Disclosure}

The authors declare that there is no conflict of interest.

\section{REFERENCES}

[1] Herlitz J, et al. Characteristics and outcome among patients suffering from in hospital cardiac arrest in relation to the interval between collapse and start of CPR. 2002; 53: 21-27. https://doi .org/10 .1016/S0300-9572(01) 00485-3

[2] Neumar RW, et al. Part 1: Executive Summary. Circulation. 2015; 132: S315-S367. PMid:26472989 https://doi.org/10.1161/ CIR. 0000000000000252

[3] Meaney PA, et al. Cardiopulmonary Resuscitation Quality: Improving Cardiac Resuscitation Outcomes Both Inside and Outside the Hospital. Circulation. 2013; 128: 417-435. PMid:23801105 https://doi.org/10.1161/CIR.0b013e31829d8654

[4] Chua WL, et al. Factors influencing the activation of the rapid response system for clinically deteriorating patients by frontline ward clinicians: a systematic review. International Journal for Quality in Health Care. 2017; 29: 981-998. PMid:29177454 https: //doi.org/10.1093/intqhc/mzx149

[5] Mäkinen M, et al. Nurses' attitudes towards resuscitation and national resuscitation guidelines-Nurses hesitate to start CPR-D. Resuscitation. 2009; 80: 1399-1404. PMid:19818547 https://doi.org/10 .1016/j.resuscitation. 2009.08 .025

[6] Gombotz H, et al. In-hospital cardiac resuscitation outside the ICU by nursing staff equipped with automated external defibrillators-the first 500 cases. Resuscitation. 2006; 70: 416-22. PMid:16908093 https: //doi.org/10.1016/j.resuscitation.2006.02.006

[7] Wynne G, et al. Inability of trained nurses to perform basic life support. BMJ. 1987; 294: 1198-1199. PMid:3109579 https://doi. org/10.1136/bmj .294.6581.1198

Published by Sciedu Press
[8] Verplancke T, et al. Determinants of the quality of basic life support by hospital nurses. Resuscitation. 2008; 77: 75-80. PMid:18083286 https://doi.org/10.1016/j.resuscitatio n.2007.10.006

[9] Murphy M, Fitzsimons D. Does attendance at an immediate life support course influence nurses' skill deployment during cardiac arrest? Resuscitation. 2004; 62: 49-54. PMid:15246583 https : //doi.org/10.1016/j.resuscitation.2004.01.033

[10] Padilha JM, et al. Clinical Virtual Simulation in Nursing Education: Randomized Controlled Trial. J Med Internet Res. 2019; 21: e11529. PMid:30882355 https://doi.org/10.2196/11529

[11] Williams KL, et al. Mock Code: A Code Blue Scenario Requested by and Developed for Registered Nurses. Cureus. 2016; 8: e938. https://doi.org/10.7759/cureus . 938

[12] Wallace DR, Gill JM. The value of simulation debriefing in launching reduced anxiety and improved self-confidence in the clinical setting for accelerated baccalaureate nursing students. Journal of Nursing Education and Practice. 2019; 9(7): 31-37. https : //doi .org/10 .5430/jnep.v9n7p31

[13] Delac K. Five Alive Using Mock Code Simulation to Improve Responder Performance During the First 5 Minutes of a Code. Critical Care Nursing Quarterly. 36, 244-250. PMid:23470711 https: //doi.org/10.1097/CNQ.0b013e3182846f1a

[14] Buckley T, Gordon C. The effectiveness of high fidelity simulation on medical-surgical registered nurses' ability to recognise and respond to clinical emergencies. Nurse Educ Today. 2011; 31: 716-21. PMid:20573428 https://doi.org/10.1016/j.nedt.2010.04 .004 
[15] Huseman KF. Improving code blue response through the use of simulation. J Nurses Staff Dev. 2012; 28: 120-4. PMid:22617782 https://doi.org/10.1097/NND.0b013e3182551506

[16] Cyr AA, Anderson ND. Learning from your mistakes: does it matter if you're out in left foot, I mean field? Memory. 2018; 26: 12811290. PMid:29659332 https ://doi .org/10.1080/09658211.2 018.1464189

[17] Simko LC, et al., Simulation and mock code: A safe way for nursing students to learn. Journal of Nursing Education and Practice. 2014; 4(7): 95-103. https://doi .org/10.5430/jnep.v4n7p95

[18] Cheng A, et al. Part 6: Resuscitation Education Science: 2020 American Heart Association Guidelines for Cardiopulmonary Resuscitation and Emergency Cardiovascular Care. Circulation. 2020.

[19] Berg KM, et al. Part 7: Systems of Care: 2020 American Heart Association Guidelines for Cardiopulmonary Resuscitation and Emergency Cardiovascular Care. Circulation. 2020.

[20] The Joint Commission. 2009 National patient safety goals hospital program. 2009.

[21] Aase I, et al. Interprofessional communication in a simulationbased team training session in healthcare: A student perspective. Journal of Nursing Education and Practice. 2016; 6(7): 91-103. https://doi.org/10.5430/jnep.v6n7p91

[22] Vecchia ED, Sparacino L. High fidelity simulator experience for enhancing communication effectiveness: Applications to quality and safety education for nurses. Journal of Nursing Education and Practice. 2015; 5(9): 78-82. https://doi.org/10.5430/jnep.v5n $9 \mathrm{p} 78$

[23] Garbee DD, et al. Effectiveness of teamwork and communication education using an interprofessional high-fidelity human patient simulation critical care code. Journal of Nursing Education and Practice. 2012.

[24] Cook DA, et al. Technology-enhanced simulation for health professions education: a systematic review and meta-analysis. JAMA. 2011; 306: $978-88$

[25] Smallheer B, Hunt J, Smith J. Using Critical Care Simulations to Prepare Nursing Students for Capstone Clinical Experiences. Dimens Crit Care Nurs. 2018; 37: 69-77. PMid:29381501 https: //doi.org/10.1097/DCC.0000000000000283

[26] Jensen TW, et al. A nationwide investigation of CPR courses, books, and skill retention. Resuscitation. 2019; 134: 110-121. PMid:30385384 https://doi.org/10.1016/j.resuscitatio n. 2018.10.029

[27] Fisher R. Designing the simulation learning environment: An active engagement model. Journal of Nursing Education and Practice. 2015; 3(3): 1-12. https://doi.org/10.5430/jnep.v3n3p1

[28] Cobb LA. Influence of Cardiopulmonary Resuscitation Prior to Defibrillation in Patients With Out-of-Hospital Ventricular Fibrillation. JAMA. 1999; 281: 1182. PMid:10199427 https://doi.org/10 $.1001 /$ jama. 281.13 .1182

[29] Toubasi S, et al. Impact of simulation training on Jordanian nurses' performance of basic life support skills: A pilot study. Nurse Education Today. 2015; 35: 999-1003. PMid:25935665 https: //doi.org/10.1016/j.nedt.2015.03.017

[30] Hopstock LA. Cardiopulmonary resuscitation; use, training and self-confidence in skills. A self-report study among hospital personnel. Scandinavian Journal of Trauma, Resuscitation and Emergency Medicine. 2008; 16: 18. PMid:19087259 https ://doi.org/10.1 186/1757-7241-16-18

[31] Hamilton R. Nurses' knowledge and skill retention following cardiopulmonary resuscitation training: a review of the literature. Journal of Advanced Nursing. 2005; 51: 288-297. PMid:16033596 https://doi.org/10.1111/j.1365-2648.2005.03491.x
[32] Marteau TM, et al. Resuscitation: experience without feedback increases confidence but not skill. BMJ. 1990.

[33] Almeida AOD, et al. Theoretical knowledge of nurses working in non-hospital urgent and emergency care units concerning cardiopulmonary arrest and resuscitation. Revista Latino-Americana de Enfermagem. 2011; 19: 261-268. PMid:21584371 https://doi.org/ 10.1590/S0104-11692011000200006

[34] Woollard M, et al. Optimal refresher training intervals for AED and CPR skills: A randomised controlled trial. 2006; 71: 237-247. PMid:17010497 https://doi.org/10.1016/j.resuscitatio n. 2006.04 .005

[35] Nyman J, Sihvonen M. Cardiopulmonary resuscitation skills in nurses and nursing students. Resuscitation. 2000; 47: 179-184. https://doi.org/10.1016/S0300-9572(00)00226-4

[36] Barnsley L, et al. Clinical skills in junior medical officers: a comparison of self-reported confidence and observed competence. Med Educ. 2004; 38: 358-67. PMid:15025637 https ://doi .org/10.1046/ j.1365-2923.2004.01773.x

[37] Berger C, et al. Combination of problem-based learning with highfidelity simulation in CPR training improves short and long-term CPR skills: a randomised single blinded trial. BMC Medical Education. 2019.

[38] Adib-Hajbaghery M, Sharifi N. Effect of simulation training on the development of nurses and nursing students' critical thinking: A systematic literature review. Nurse Educ Today. 2017; 50: 17-24. PMid:28011333 https://doi.org/10.1016/j.nedt.2016.12 .011

[39] Kaddoura MA. New graduate nurses' perceptions of the effects of clinical simulation on their critical thinking, learning, and confidence. J Contin Educ Nurs. 2010; 41: 506-16. PMid:20672760 https://doi.org/10.3928/00220124-20100701-02

[40] Kirkpatrick DL. Evaluation of training. In R. L. Craig (Ed.),Training and development handbook: A guide to human resourcedevelopment. New York: McGraw Hill. 1976.

[41] Skrifvars MB, et al. Improved survival after in-hospital cardiac arrest outside critical care areas. Acta Anaesthesiologica Scandinavica. 2005. PMid:16223402 https://doi .org/10.1111/j .1399-657 $6.2005 .00847 . \mathrm{x}$

[42] Athanasuleas CL, et al. Sudden cardiac death: Directing the scope of resuscitation towards the heart and brain. Resuscitation. 2006; 70: 44-51. PMid:16759784 https://doi.org/10.1016/j.resuscitation.2005.11.017

[43] Truhlár A, et al. European Resuscitation Council Guidelines for Resuscitation 2015. Resuscitation. 2015; 95: 148-201. PMid:26477412 https://doi.org/10.1016/j.resuscitatio n. 2015.07.017

[44] Kalogeris T, et al. Cell Biology of Ischemia/Reperfusion Injury. 2012; 229-317. PMid:22878108 https://doi.org/10.1016/B978-0 -12-394309-5.00006-7

[45] Oh SI, Han SS. A Study on the Sustainable Effects of Reeducation on Cardiopulmonary Resuscitation on Nurses' Knowledge and Skills. Journal of Korean Academy of Nursing. 2008; 38: 383. PMid:18604147 https://doi.org/10.4040/jkan.2008.38.3 .383

[46] Shinozaki K, Nonogi H, Nagao K, et al. Strategies to Improve Cardiac Arrest Survival: A Time to Act. 2015. PMid:29123754 https://doi.org/10.1002/ams2.192

[47] VHA Directive 1177 Cardiopulmonary Resuscitation. Available from: https://www.va.gov/vhapublications/ViewPublica tion. asp?pub_ID $=9132$

[48] Preusch MR, et al. Resuscitation Guidelines 2005: does experienced nursing staff need training and how effective is it? The American 
Journal of Emergency Medicine. 2010; 28: 477-484. PMid:20466229 https://doi.org/10.1016/j.ajem.2009.01.040

[49] Dine CJ. Improving cardiopulmonary resuscitation quality and resuscitation training by combining audiovisual feedback and debriefing. Critical Care Medicine. 2008; 36: 2817-2822. PMid:18766092
https://doi.org/10.1097/CCM.0b013e318186fe37

[50] Seethala RR. Approaches to improving cardiac arrest resuscitation performance. Current Opinion in Critical Care. 2010; 16: 196-202. PMid:20305553 https://doi.org/10.1097/MCC.0b013e3283 $38 \mathrm{c} 121$ 